\title{
Single nucleotide polymorphisms in interleukin-6 and their association with venous thromboembolism
}

\author{
UMESH YADAV*, AILIMAN MAHEMUTI*, XUEMEI HU*, KAILIBINURE ABUDUREHEMAN*, \\ YUNING XIA, BAOPENG TANG and HALMURAT UPUR
}

Department of Cardiology, The First Affiliated Hospital of Xinjiang Medical University, Urumqi, Xinjiang 830054, P.R. China

Received February 15, 2014; Accepted November 25, 2014

DOI: $10.3892 / \mathrm{mmr} .2015 .3248$

\begin{abstract}
The aim of the present study was to reveal the contribution of single nucleotide polymorphisms of the interleukin-6 (IL-6) gene and the progression of venous thromboembolism (VTE). A case-control study composed of 246 VTE patients, including 160 from the Han population (76 males and 84 females, mean age $57.41 \pm 13.25$ years), 86 from the Uyghur population (41 males and 45 females, mean age $51.61 \pm 13.73$ years) and 292 gender and ethnicity-matched control participants, including 170 from the Han population (91 males and 79 females, mean age 55.82 \pm 11.83 years) and 122 from the Uyghur population (64 males and 58 females, mean age $53.52 \pm 13.64$ years) were enrolled in the present study. The results demonstrated that the serum levels of IL-6, C-reactive protein (CRP), D-dimer, fibrinogen, plasminogen activator inhibitor-1 and leptin were significantly higher in the VTE group compared with the control group $(\mathrm{P}<0.05)$. The frequencies of the $-572 \mathrm{C} / \mathrm{G}$ promoter polymorphisms of the IL-6 genotypes CC, CG and GG were identified to be 34, 48 and $18 \%$ in the Han population and 33,47 and $20 \%$ in the Uyghur population, respectively. The allele frequency distributions of the $\mathrm{C}$ and $\mathrm{G}$ alleles were 58 and $42 \%$ in the Han population and 56 and $43 \%$ in the Uyghur population, respectively. Significant differences were identified in the $-572 \mathrm{C} / \mathrm{G}$ promoter polymorphisms between the VTE group and the control group $(\mathrm{P}<0.05)$. For the $-597 \mathrm{G} / \mathrm{A}$ polymorphism, all individuals carried the GG and GA genotype; AA genotypes were not detected. Logistic regression analysis was used to
\end{abstract}

Correspondence to: $\mathrm{Dr}$ Ailiman Mahemuti, Department of Cardiology, The First Affiliated Hospital of Xinjiang Medical University, 137 Liyushan Road, Urumqi, Xinjiang 830054, P.R. China

E-mail: nayisha2006@hotmail.com; 1519362315@qq.com

${ }^{*}$ Contributed equally

Key words: venous thromboembolism, Uyghur, gene polymorphism, interleukin-6 identify the risk factors for VTE, adjusting by confounding factors, the results of which demonstrated that the $\mathrm{CC}$ homozygote of the IL-6 -572G/C, CRP, IL-6 and high-density lipoprotein-cholesterol were independent risk factors of VTE $(\mathrm{P}<0.05)$. In conclusion, the $-572 \mathrm{G} / \mathrm{C}$ genotype of IL-6 may be a genetic marker of VTE in the Han and Uyghur populations.

\section{Introduction}

Venous thromboembolism (VTE) is a severe health problem with pathogenic contributions from genetic and environmental components, which have been poorly investigated in non-European populations and those outside North America $(1,2)$. Although ethnic differences in the occurrence of VTE have been reported for several years and the risk of genetic and environmental factors is known to vary depending on ethnicity, the impact of these differences on the incidence of VTE remains to be clarified (3). Outside North America and Europe, data concerning the risk factors for VTE incidence are limited. In addition, $30 \%$ of VTE incidence remains unexplained, however, in previous years studies have focused on inflammatory factors, their gene polymorphisms and the progression of VTE (4-8).

Interleukin-6 (IL-6) is a circulating cytokine known to be affected by a number of environmental and genetic factors, which subsequently affects individual susceptibility to VTE. IL-6 regulates the inflammatory reaction in vessel walls, accelerates bone restoration and is critical in atherogenesis and thrombosis (9-13). IL-6 (572G/C) polymorphisms are associated with elevated IL-6 production or protein expression in vivo and in vitro. The $\mathrm{C}$ allele of $-572 \mathrm{G} / \mathrm{C}$ is associated with increased concentrations of IL-6 (14). Elevated levels of IL-6 are associated with a 2 -fold risk of developing VTE and recurrent VTE (15). Consequently, it was hypothesized that IL-6 genetic polymorphisms may represent a candidate gene for VTE. Empirical data from different ethnic populations have indicated that genetic factors are closely associated with the development of VTE (16). The frequency of the $-572 \mathrm{C}$ allele is reported to be 0.0055 in the English population and 0.0019 in the Scottish population (17), compared with a frequency of 0.15 in the Indian population (18) and 0.419 in the Han Chinese population (9). Zheng et al reported that the $-572 \mathrm{G} / \mathrm{C}$ 
polymorphism of the IL-6 gene may possibly lead to the development of coronary heart disease (19). The total Uyghur population was 8.4 million in 2000 and $99.4 \%$ of the total population of Uyghurs live in the Xinjiang Uyghur Autonomous Region, which is situated in the center of Asia (20). As stated in our preliminary research, the main reason for the difference in prevalence of VTE is possibly the difference in diet between the Chinese Han and Uyghur populations. Compared with the Han population, the Uyghur population consumed more pasta, meat and milk products. Thus, the prevalence of obesity, particularly central obesity in the Uyghur population was higher compared with that in the Han Chinese population (21). There are $>13$ ethnic groups living in this area. A number of ethnicities, including the Uyghur (48\%), Han (38\%) and Kazakh people (7\%), are present in this area (22). Due to the religious beliefs of the Uyghur population, lifestyle, customs and marital practices are different from other ethnic groups in China. This population has lived in a relatively fixed location for significant time periods, leading to the development of a population with a number of stable genetic features. Multiple studies have also identified that the Uyghur allele distribution is distinctly different from that of other populations in Northwest China, including Han, Hui and Mongolian, which therefore indicates that the prevalence of VTE differs between these populations (23-26). Several studies have reported that the main risk factor for coronary artery disease (27), hypertension (28) and atrial fibrillation (29) is different among these ethnic groups in Xinjiang. To date, to the best of our knowledge, no data are available regarding the mutations in the IL-6 gene hypothesized to be responsible for the prevalence of VTE in the Chinese Uyghur population. Therefore, screening for possible mutations and polymorphisms of the IL- 6 gene was performed and the association between the genotypes of this gene and the progression of VTE in the Chinese Han and Chinese Uyghur population was assessed.

\section{Materials and methods}

Study population. The present study included two patient populations (Han and Uyghur) with documented VTE. A total of 160 Han patients and 86 Uyghur patients diagnosed with VTE at the First Affiliated Hospital of Xinjiang Medical University (Xinjiang, China) between 2008 and 2010 were recruited (Table I). The Han and Uyghur populations were termed the first and second VTE group, respectively. The number of patients with pulmonary embolism (PE) alone, deep vein thrombosis (DVT) alone and PE-DVT were 101, 23 and 36 in the first VTE group and 40,18 and 28 in the second VTE group, respectively. Patients with PE were diagnosed according to the results of pulmonary CT angiography, pulmonary artery magnetic resonance imaging and autopsy. Patients with DVT were diagnosed according to the results of compressed ultrasound and venography of veins in the lower limbs. The patients eligible for inclusion criteria, were successively selected using standardized criteria (29). Patients in the control group at the time of enrollment did not have a personal or family history of VTE. Systemic arterial hypertension was defined as a systolic blood pressure of $\geq 140 \mathrm{mmHg}$ and/or a diastolic blood pressure of $\geq 90 \mathrm{~mm} \mathrm{Hg}$, on at least two different occasions or patients receiving antihypertensive treatment. Patients that recorded habitual smoking in the previous 6 months were considered to be current smokers. For each VTE case group, healthy participants matched for ethnicity, gender and age were used as the controls. The control subjects were recruited from the Medical Centre of the First Affiliated Hospital of Xinjiang Medical University. The present study was authorized by the Ethics Committee of the First Affiliated Hospital of Xinjiang Medical University. Written informed consent was obtained from all participants.

Blood sampling. Following overnight fasting for $12 \mathrm{~h}$, venous blood was collected in ethylenediaminetetraacetic acid. The samples were promptly centrifuged at $1,006.2 \mathrm{x} \mathrm{g}$ for $10 \mathrm{~min}$ following collection and stored at $-20^{\circ} \mathrm{C}$. The lymphocyte secretion medium was used to isolate white blood cells. Phenol chloroform was used for the extraction of genomic DNA.

Biochemical determinations. Assessment of serum levels of total cholesterol, triglyceride (TG), high-density lipoprotein cholesterol (HDL-C), platelet count, uric acid and creatine kinase (CK) was performed using approved and regular procedures at the Central Laboratory of First Affiliated Hospital of Xinjiang Medical University. An enzyme linked immunosorbent assay (ELISA) approach using a microplate reader (Bio-Rad, Hercules, CA, USA) was used for detecting the level of C-reactive protein (CRP), D-dimer (DD), plasminogen activator inhibitor-1 (PAI-1) and leptin using a human IL-6 ELISA kit, human CRP ELISA kit, human DD ELISA kit, human PAI-1 ELISA kit and human leptin ELISA kit, respectively, in the VTE and control groups. All ELISA kits were purchased from Groundwork Biotechnology Diagnosticate (San Diego, CA, USA).

A total of $401 \mathrm{VTE}$ cases and 379 controls were investigated for the $-597 \mathrm{G} / \mathrm{C}$ genotyping and $-572 \mathrm{G} / \mathrm{C}$ single nucleotide polymorphisms (SNPs) in the promoter of the IL-6 gene were analyzed using polymerase chain reaction (PCR) restriction fragment length polymorphism (Fig. 1). PCR was administered utilizing the following primers purchased from TIB Molbiol (Berlin, Germany): IL-6 597G/A, forward 5'-AAAGGAGTCACACACTCC-3' and reverse 5'-GCGTTCCAGTTAATTTGTATTTG-3' and IL-6 572C/G, forward 5'-AAAGGAGTCACACACTCC-3' and reverse 5'-GCGTTCCAGTTAATTTGTATTTG-3'. The reaction was performed in a $10 \mu \mathrm{l}$ sample volume using $0.25 \mu \mathrm{g} / \mathrm{ml}$ DNA as a template, $50 \mathrm{mmol} / 1 \mathrm{MgCl}_{2}, 10 \mathrm{mmol} / \mathrm{l} \mathrm{dNTPs}$ (Boehringer Ingelheim, Ingelheim, Germany), $5 \mathrm{U} / \mu 1$ Taq DNA polymerase (CinnaGen, Tehran, Iran) and $10 \mathrm{pM}$ of primers.

The amplification parameters for $-597 \mathrm{G} / \mathrm{C}$ and $-572 \mathrm{C} / \mathrm{G}$ were $95^{\circ} \mathrm{C}$ for $5 \mathrm{~min}$ and then five cycles of $95^{\circ} \mathrm{C}$ for $30 \mathrm{sec}, 55^{\circ} \mathrm{C}$ for $30 \mathrm{sec}$ and $72^{\circ} \mathrm{C}$ for $30 \mathrm{sec}$ followed by 30 cycles of $95^{\circ} \mathrm{C}$ for $30 \mathrm{sec}, 58^{\circ} \mathrm{C}$ for $30 \mathrm{sec}$ and $72^{\circ} \mathrm{C}$ for $30 \mathrm{sec}$. The samples were incubated at $72^{\circ} \mathrm{C}$ for an additional $5 \mathrm{~min}$ to complete the final extension step following the final cycle. The PCR products were digested with restriction endonucleases obtained from Fermantes (Vilnius, Lithuania) to determine the genotype of every subject. FokI was used for digestion of the PCR products containing position $-597 \mathrm{G} / \mathrm{C}$ and $\mathrm{BrsBI}$ was used for position $-572 \mathrm{C} / \mathrm{G}$. Subsequently, the DNA fragments were separated using a $3 \%$ agarose gel for the two samples and were detected by ethidium bromide staining. The PCR product size was 198 bp 

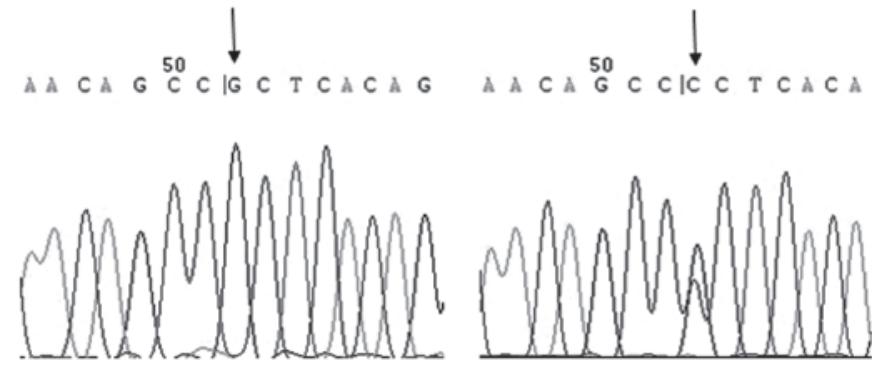

Figure 1. Polymerase chain reaction product sequencing diagram of the interleukin-6-572C/G gene polymorphism (arrows indicate the position of the base mutation)

for the $-597 \mathrm{G} / \mathrm{C}$ polymorphism. The PCR product containing the $\mathrm{G}$ allele was digested into two fragments of 198 and $175 \mathrm{bp}$ (Fig. 2), while the PCR product containing the $\mathrm{C}$ allele was not able to be cut by the enzyme. For $-572 \mathrm{G} / \mathrm{C}$, the PCR product size was 232 bp (Fig. 3). The PCR product containing the $\mathrm{C}$ allele was digested into two fragments of 149 and $83 \mathrm{bp}$. The PCR product containing the $\mathrm{G}$ allele was unaltered.

Statistical analysis. Statistical analysis was performed using SPSS 17.0 software for Windows (SPSS, Inc., Chicago, IL, USA). Complete genotype frequencies were assessed in the two groups separately by using the Hardy-Weinberg equilibrium. While IL-6 and CRP values did not conform to a normal distribution, the Mann-Whitney U test and the Kruskal-Wallis test were applied for comparison between groups. Continuous variables were correlated applying an unpaired t-test and discrete variables with the $\chi^{2}$ test. The IL- 6 and CRP values are expressed as the median and range and the remaining variables are expressed as the mean \pm standard deviation or a ratio (\%). Genotype and allele frequency differences were distinguished among the patient and control groups using the $\chi^{2}$ test, where appropriate. A logistic regression model was used to calculate odds ratios (ORs) and their $95 \%$ confidence intervals $(95 \% \mathrm{CI})$ to assess the strength of the association between individual genetic polymorphisms and the risk of VTE. All regression analyses were adjusted for potential confounders. $\mathrm{P}<0.05$ was considered to indicate a statistically significant difference.

\section{Results}

Clinical characteristics of the patients. The main characteristics of the patients and controls are summarized in Table I. No significant differences were identified between the two groups with regards to the distribution of age, gender, systolic blood pressure, diastolic blood pressure or the levels of CK, CK-MB and HDL-C (all P>0.05). However, smoking and levels of IL-6, CRP, leptin, TG, low-density lipoprotein cholesterol (LDL-C) and body mass index (BMI) were significantly higher in the case group compared with the control group (all $\mathrm{P}<0.05$ ).

Genotypes and allele distribution of VTE patients and control participants in the two populations. The genotype and allele frequencies of IL-6 in controls and patients with VTE are shown in Table II. The distribution of genotypes was not observed to be significantly deviated from the Hardy-Weinberg equilibrium in the VTE and control groups (all $\mathrm{P}>0.05$ ). The $-572 \mathrm{C} / \mathrm{G}$

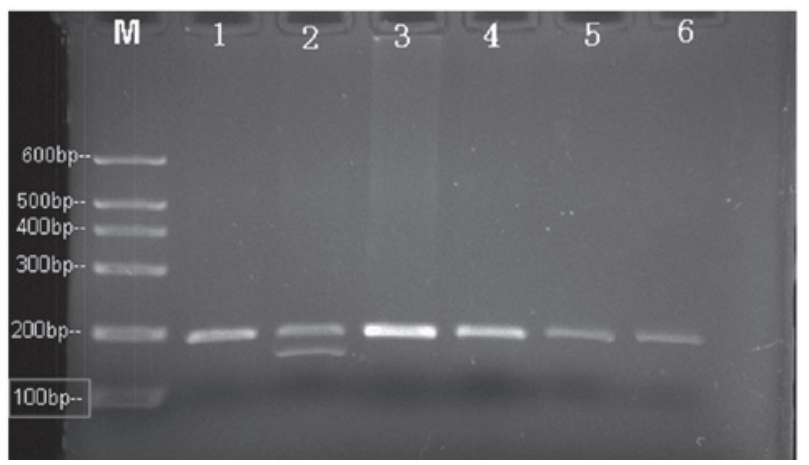

Figure 2. Restriction fragment length polymorphism analyses of interleukin-6-597G/A for determination of genotype. The GA genotype exhibited two bands of 198 and $175 \mathrm{bp}$ (lane 2). The GG genotype exhibited one band of $198 \mathrm{bp}$ (lanes 1,3, 4, 5 and 6).

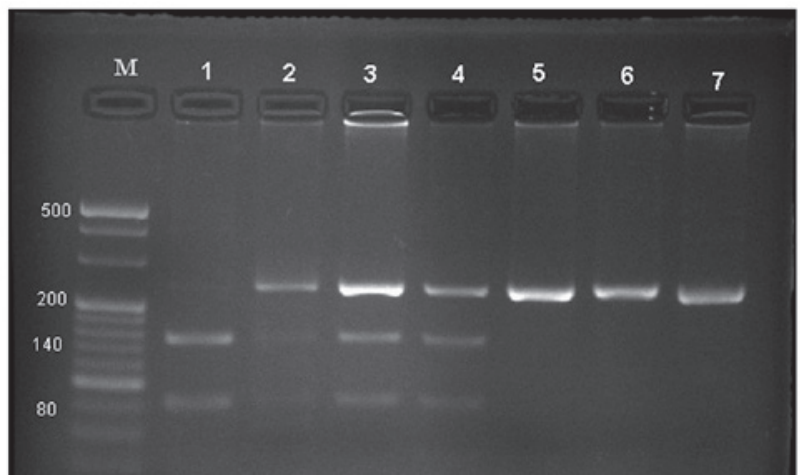

Figure 3. Restriction fragment length polymorphism analyses of interleukin-6-572G/C for the determination of genotype. The GG genotype exhibited two bands of 149 and 83 bp (lane 1). The GC genotype exhibited three bands of 232, 149 and 83 bp (lanes 2, 3 and 4). The CC genotype exhibited one band of 232 bp (lanes 5 and 6).

promoter polymorphisms of the IL-6 gene contained CC, $\mathrm{CG}$ and $\mathrm{GG}$ genotypes. The gene frequencies of the $-572 \mathrm{C} / \mathrm{G}$ promoter polymorphisms in the Han population for $\mathrm{CC}, \mathrm{CG}$ and GG were $41.25,46.25$ and $12.50 \%$, respectively in the VTE group, while it was $26.47,50.00 \%$ and $23.53 \%$, respectively in the control group. The frequencies of $\mathrm{C}$ and $\mathrm{G}$ alleles of IL-6 -572C/G were 64.37 and $35.63 \%$, respectively, in the VTE group and 51.47 and $48.53 \%$, respectively, in the control group in the Han population. Significant differences were identified in the $-572 \mathrm{C} / \mathrm{G}$ promoter polymorphism genotypes and allele distribution between the VTE group and control group in the Han population $(\mathrm{P}<0.05)$. The gene frequencies of the $-572 \mathrm{C} / \mathrm{G}$ promoter polymorphism in the Uyghur population for $\mathrm{CC}, \mathrm{CG}$ and GG were $40.70,45.35$ and $13.95 \%$, respectively in the VTE group, while it was $25.41,48.36$ and $26.23 \%$, respectively in the control group. The frequencies of $\mathrm{C}$ and $\mathrm{G}$ alleles of IL-6 $-572 \mathrm{C} / \mathrm{G}$ were 63.37 and $36.63 \%$ in the VTE group and 49.59 and $50.41 \%$ in the control group in the Uyghur population. There was a significant difference in the $-572 \mathrm{C} / \mathrm{G}$ promoter polymorphisms between the VTE and control group in the Uyghur population $(\mathrm{P}<0.05)$. However, no significant difference was identified in the $-572 \mathrm{C} / \mathrm{G}$ promoter polymorphism allele distribution between the VTE group and the control group in the Uyghur population $(\mathrm{P}<0.05)$. In patients with the 
Table I. Clinical characteristics and blood parameters measured in the study subjects of the Uyghur and Han population.

\begin{tabular}{|c|c|c|c|c|c|c|}
\hline \multirow[b]{2}{*}{ Characteristic } & \multicolumn{3}{|c|}{ Uyghur } & \multicolumn{3}{|c|}{ Han } \\
\hline & VTE $(n=86)$ & Control $(n=122)$ & P-value & $\operatorname{VTE}(n=160)$ & Control $(n=170)$ & P-value \\
\hline Male (\%) & $41(47.67)$ & $64(52.46)$ & 0.574 & $76(47.50)$ & $91(53.53)$ & 0.322 \\
\hline Age (years) & $51.61 \pm 13.73$ & $53.52 \pm 13.64$ & 0.386 & $57.41 \pm 13.25$ & $55.82 \pm 11.83$ & 0.291 \\
\hline Smoking (\%) & $43(50)$ & $43(35.25)$ & 0.045 & $91(56.88)$ & $65(38.24)$ & 0.001 \\
\hline Drinking (\%) & $55(63.95)$ & $86(70.49)$ & 0.000 & $70(43.75)$ & $53(31.18)$ & 0.023 \\
\hline Hypertension (\%) & $24(27.91)$ & $28(22.95)$ & 0.422 & $102(63.75)$ & $90(52.94)$ & 0.058 \\
\hline Diabetes (\%) & $18(20.93)$ & $14(11.48)$ & 0.079 & $33(20.63)$ & $23(13.53)$ & 0.106 \\
\hline Obesity (\%) & $45(52.33)$ & $38(31.15)$ & 0.004 & $70(43.75)$ & $53(31.18)$ & 0.023 \\
\hline BMI (kg/m2) & $27.61 \pm 3.13$ & $29.32 \pm 2.76$ & 0.006 & $25.90 \pm 3.63$ & $24.52 \pm 2.74$ & 0.000 \\
\hline $\mathrm{Cr}(\mu \mathrm{mol} / 1)^{\mathrm{a}}$ & $71(55,93)$ & $87(78,98)$ & 0.531 & $81(63,100)$ & $88(74,99)$ & 0.898 \\
\hline $\mathrm{UA}(\mu \mathrm{mol} / \mathrm{l})^{\mathrm{a}}$ & $251(177,336)$ & $312(251,375)$ & 0.314 & $317(208,371)$ & $315(272,354)$. & 0.548 \\
\hline $\mathrm{TG}(\mu \mathrm{mol} / \mathrm{l})^{\mathrm{a}}$ & $1.21(0.85,1.51)$ & $1.86(1.18,2.35)$ & 0.000 & $1.39(0.90,1.73)$ & $1.60(1.14,2.03)$ & 0.001 \\
\hline $\mathrm{TC}(\mu \mathrm{mol} / \mathrm{l})$ & $3.81 \pm 1.27$ & $4.16 \pm 1.91$ & 0.046 & $4.16 \pm 1.0$ & $3.81 \pm 0.92$ & 0.002 \\
\hline $\mathrm{HDL}(\mu \mathrm{mol} / \mathrm{l})$ & $0.95 \pm 0.38$ & $0.97 \pm 0.25$ & 0.701 & $1.05 \pm 0.29$ & $0.90 \pm 0.51$ & 0.003 \\
\hline LDL-C $(\mu \mathrm{mol} / \mathrm{l})$ & $2.43 \pm 0.78$ & $2.50 \pm 0.76$ & 0.561 & $2.47 \pm 0.77$ & $2.54 \pm 1.06$ & 0.499 \\
\hline $\mathrm{CK}(\mathrm{U} / \mathrm{l})^{\mathrm{a}}$ & $51.21(29.62,72.11)$ & $68.01(45.52,91.58)$ & 0.412 & $53.55(28.53,75.22)$ & $65.08(54.31,82.53)$ & 0.541 \\
\hline CK-MB (U/1) ${ }^{\mathrm{a}}$ & $10.02(7.36,14.81)$ & $11.91(8.72,15.63)$ & 0.665 & $9.76(5.51,14.91)$ & $12.95(8.73,15.12)$ & 0.661 \\
\hline FIB $(g / l)$ & $6.47 \pm 2.74$ & $3.61 \pm 1.22$ & 0.054 & $6.61 \pm 4.52$ & $3.52 \pm 1.51$ & 0.067 \\
\hline $\mathrm{LDH}(\mathrm{U} / \mathrm{l})^{\mathrm{a}}$ & $220(155,273)$ & $164(127,187)$ & 0.412 & $222(179,269)$ & $137(121,161)$ & 0.871 \\
\hline $\operatorname{ALP}(\mathrm{U} / 1)^{\mathrm{a}}$ & $78.31(68.14,101.12)$ & $75.51(67.01,83.82)$ & 0.073 & $83.48(62.24,97.13)$ & $63.52(52.71,80.28)$ & 0.061 \\
\hline Leptin $(\mu \mathrm{g} / \mathrm{l})$ & $11.81 \pm 3.26$ & $3.81 \pm 1.07$ & 0.031 & $13.81 \pm 6.11$ & $3.79 \pm 1.55$ & 0.025 \\
\hline IL-6 (pg/ml) & $61.14(31.3-94.27)$ & $68.6(39.22-106.94)$ & $0.002^{\mathrm{b}}$ & $65.1(30.83-93.65)$ & $64.5(40.44-112.83)$ & $0.002^{\mathrm{b}}$ \\
\hline CRP (pg/ml) & $27.82(21.12-36.43)$ & $21.60(15.53-24.26)$ & $0.000^{\mathrm{b}}$ & $26.7(21.23-35.14)$ & $22.56(15.35-25.32)$ & $0.000^{\mathrm{b}}$ \\
\hline
\end{tabular}

BMI, body mass index; Cr, creatinine; UA, uric acid; TG, triglyceride; TC, total cholesterol; HDL-C, high-density lipoprotein cholesterol; LDL-C, low-density lipoprotein cholesterol; CK, creatine kinase; CK-MB, creatine kinase isoenzyme; FIB, fibrinogen; LDH, lactate dehydrogenase; ALP, alkaline phosphatase; IL-6, interleukin-6; CRP, C-reactive protein; VTE, venous thromboembolism. ${ }^{\text {b }}<<0.05$, case vs. control; ${ }^{a} \mathrm{P}<0.05$, genotype and mutation frequency in VTE group vs. control.

-597G/A polymorphism, individuals all carried the GG and GA type; AA genotypes were not detected (Fig. 2).

Identification of independent risk factors for VTE. Following adjustment for the following confounding factors of age, gender, hypertension, family history, hyperlipidemia and smoking, a multiple logistic regression model revealed four independent factors (Tables III and IV), including CRP $(\mathrm{OR}=1.079 ; 95 \% \mathrm{CI}=1.048-1.110 ; \mathrm{P}<0.05), \mathrm{IL}-6$ (OR=1.005; $95 \% \mathrm{CI}=1.033-1.010 ; \mathrm{P}<0.05)$, obesity $(\mathrm{OR}=0.381 ; 95 \%$ $\mathrm{CI}=0.187-0.796 ; \mathrm{P}<0.05)$ and IL-6 -572CC $(\mathrm{OR}=2.853 ; 95 \%$ $\mathrm{CI}=1.248-1.110 ; \mathrm{P}<0.05)$ for VTE in the Uyghur population. Regarding the VTE group in the Han population the data revealed: $\mathrm{BMI}(\mathrm{OR}=1.110 ; 95 \% \mathrm{CI}=1.033-1.193$; $\mathrm{P}<0.05), \mathrm{CRP}$ $(\mathrm{OR}=1.052 ; 95 \% \mathrm{CI}=1.044-1.124 ; \mathrm{P}<0.05), \mathrm{IL}-6(\mathrm{OR}=1.079$; 95\% CI=1.041-2.115; $\mathrm{P}<0.05), \mathrm{IL}-6 \quad-572 \mathrm{CC} \quad(\mathrm{OR}=1.762$; 95\% $\mathrm{CI}=1.376-5.312 ; \mathrm{P}<0.05), \mathrm{HDL}-\mathrm{C}(\mathrm{OR}=0.381 ; 95 \%$ $\mathrm{CI}=0.187-0.796 ; \mathrm{P}<0.05)$. In addition, the $\mathrm{CC}$ homozygosity of the IL-6 $-572 \mathrm{C} / \mathrm{G}$ gene was also an independent risk factor for VTE with a 2.85-fold higher relative risk of developing VTE compared with GG homozygotes in the Uyghur population $(\mathrm{OR}=2.853 ; 95 \% \mathrm{CI}=1.248-6.241 ; \mathrm{P}<0.05)$. Multiple logistic regression analysis (Tables III and IV) revealed that in the $\mathrm{CC}$ homozygotes of the IL-6 $-572 \mathrm{G} / \mathrm{C}$ polymorphism, CRP, IL-6, HDL-C and obesity were independent risk factors for VTE in the Uyghur and Han populations $(\mathrm{P}<0.05)$.

\section{Discussion}

In the present study, SNPs of IL-6 were identified to be associated with the occurrence of VTE. The inflammatory markers CRP, IL-6 and leptin; hemostasis markers, fibrinogen (FIB), DD and PAI-1 and traditional risk factors TG and LDL-C were significantly higher in the VTE group in the Uyghur and Han populations. An SNP was identified (-572G/C) and it was observed that the minor allele of $-572 \mathrm{G} / \mathrm{C}$ (SNP in IL-6) had a higher frequency in VTE patients compared with controls. To the best of our knowledge, the present study is the first to demonstrate an association between IL-6 and VTE in the Uyghur population.

The $-572 \mathrm{G} / \mathrm{C}$ and $-597 \mathrm{~A} / \mathrm{G}$ polymorphisms were genotyped and the association between IL- 6 and VTE was assessed. The frequency of the GC genotype of $-572 \mathrm{G} / \mathrm{C}$ was significantly increased in VTE patients compared with in control subjects, not only in the Han population but also in the Uyghur population. This indicated that the risk of VTE 
Table II. Genotypes and allele distribution of the VTE patients and control participants.

\begin{tabular}{|c|c|c|c|c|}
\hline Risk factors & VTE & Control & P-value & OR $(95 \% \mathrm{CI})$ \\
\hline $\begin{array}{l}\text { IL- } 6 \text { gene variants in } \\
\text { the Han population }\end{array}$ & 160 & 170 & & \\
\hline \multicolumn{5}{|l|}{$-572 \mathrm{C} / \mathrm{G}$ Alleles $(\mathrm{n}, \%)$} \\
\hline $\mathrm{C}$ & $206(64.37)$ & $175(51.47)$ & & \\
\hline G & $114(35.63)$ & $165(48.53)$ & $0.001^{\mathrm{a}}$ & $1.704(1.247-2.328)$ \\
\hline \multicolumn{5}{|l|}{ Genotypes (n, \%) } \\
\hline $\mathrm{CC}$ & $66(41.25)$ & 45 (26.47) & & \\
\hline $\mathrm{CG}$ & $74(46.25)$ & $85(50.00)$ & $0.047^{\mathrm{b}}$ & $1.685(1.031-2.752)$ \\
\hline GG & $20(12.50)$ & $40(23.53)$ & $0.001^{\mathrm{c}}$ & $2.933(1.521-5.659)$ \\
\hline $\begin{array}{l}\text { IL- } 6 \text { gene variants in } \\
\text { the Uyghur population }\end{array}$ & 86 & 122 & & \\
\hline \multicolumn{5}{|l|}{$-572 \mathrm{C} / \mathrm{G}$ Alleles $(\mathrm{n}, \%)$} \\
\hline $\mathrm{C}$ & $109(63.37)$ & $121(49.59)$ & & \\
\hline G & $63(36.63)$ & $123(50.41)$ & 0.343 & $1.347(0.785-2.312)$ \\
\hline \multicolumn{5}{|l|}{ Genotypes (n, \%) } \\
\hline $\mathrm{CC}$ & $35(40.70)$ & $31(25.41)$ & & \\
\hline $\mathrm{CG}$ & $39(45.35)$ & $59(48.36)$ & 0.111 & \\
\hline GG & $12(13.95)$ & $32(26.23)$ & $0.010^{\mathrm{d}}$ & $3.011(1.325-6.842)$ \\
\hline
\end{tabular}

Allele analysis was performed using a $\chi^{2}$ test. IL-6, interleukin-6; CC, homozygous C allele of the IL-6 gene $-572 \mathrm{C} / \mathrm{G}$; CG, heterozygous allele of the IL-6 gene -572C/G; GG, homozygous G allele of the IL-6 gene -572C/G; VTE, venous thromboembolism; CI, confidence interval; OR, odds ratio. ${ }^{\mathrm{a}} \mathrm{P}<0.05$, VTE allele vs. control allele; ${ }^{\mathrm{b}} \mathrm{P}<0.05$, VTE CG vs. control $\mathrm{CG}$; ${ }^{\mathrm{c}} \mathrm{P}<0.05$, VTE GG vs. control GG; ${ }^{\mathrm{d}} \mathrm{P}<0.05$, VTE GG vs. control GG in Uyghur population.

Table III. Logistic regression for the risk factors of venous thromboembolism in the Uyghur population.

\begin{tabular}{lccccrr}
\hline Risk factors & B & S.E. & Wald & P-value & OR & OR (95\% CI) \\
\hline IL-6 (-572CC) & 1.048 & 0.422 & 6.177 & 0.013 & 2.853 & $1.248-6.241$ \\
CRP & 0.052 & 0.043 & 22.564 & 0.002 & 1.079 & $1.048-1.110$ \\
IL-6 & 0.005 & 0.002 & 5.249 & 0.022 & 1.005 & $1.033-1.010$ \\
BMI & -0.966 & 0.376 & 6.585 & 0.010 & 0.381 & $0.187-0.796$ \\
\hline
\end{tabular}

B, coefficient for the constant (Log-odds); S.E., standard error of the coefficient; Wald, (B/S.E.)²; OR, odds ratio; CI, confidence interval; IL-6, interleukin-6; CRP, C-reactive protein; BMI, body mass index.

Table IV. Logistic regression for the risk factors of venous thromboembolism in the Han population.

\begin{tabular}{|c|c|c|c|c|c|c|}
\hline Risk factors & B & S.E. & Wald & P-value & OR & OR $(95 \% \mathrm{CI})$ \\
\hline IL-6 (-572CC) & 1.158 & 0.221 & 6.377 & 0.013 & 1.762 & $1.376-5.312$ \\
\hline BMI & 1.511 & 0.507 & 6.731 & 0.001 & 1.110 & $1.033-1.193$ \\
\hline CRP & 0.076 & 0.015 & 26.892 & 0.000 & 1.052 & $1.044-1.124$ \\
\hline IL-6 & 0.321 & 0.034 & 7.893 & 0.030 & 1.079 & $1.041-2.115$ \\
\hline
\end{tabular}

B, coefficient for the constant (Log-odds); S.E., standard error of the coefficient; Wald, (B/S.E.)²; OR, odds ratio; CI, confidence interval; IL-6, interleukin-6; CRP, C-reactive protein; BMI, body mass index.

was increased in the Uyghur and Han populations with the $\mathrm{G}$ allele. Terry et al (30) was the first study to describe the IL-6 -572 polymorphism, which is a substitution in the $5^{\prime}$ region of the IL- 6 promoter. This $\mathrm{G}$ to $\mathrm{C}$ substitution is close to a potential glucocorticoid receptor element at position -557 to -552 . The polymorphism $-572 \mathrm{G} / \mathrm{C}$ has been revealed 
to be essential for IL- 6 production, causing inflamed vascular walls and increasing the production of cytokines, including IL-6, IL-1 $\beta$ and tumor necrosis factor- $\alpha$ (TNF- $\alpha$ ), which have major regulatory roles in the hepatic synthesis of acute phase proteins, including FIB and the development of thrombosis (9,11-13,19,31-34). Several studies have demonstrated that patients with VTE are more likely to have elevated levels of plasma IL-8, IL-6, monocyte chemotactic protein-1 and TNF- $\alpha$ (10), that inflammation affects clotting factor levels (35), that an inflammatory gene is associated with VTE (36) and that acute inflammation does contribute to VTE (37). The GG and CC genotypes for IL-6-174G/C and matrix metallopeptidase-9 (MMP-9)-1562C/T polymorphisms, respectively, are associated with a risk of DVT in cancer patients by inducing the release of IL- 6 with subsequent increases in MMP-9 (31). Inflammation is possibly necessary for the initiation of venous thrombosis formation. IL-6 controls CRP gene expression (32) and the minor allele at position -572 ( $\mathrm{G}$ allele) has been revealed to be associated with increased IL-6 levels in inflammation (11). Circulating levels of CRP are under regulation of secretion of IL-6. Therefore, the ability to produce CRP and successive inflammation depends at least partially on the capacity to produce IL-6. Together, these results provided evidence for the varied effects of the IL-6 gene on plasma IL-6 levels in VTE patients. In the present study, the mean CRP and IL-6 levels were significantly higher in patients with VTE compared with the controls in the Han and Uyghur populations, which suggested that inflammation was more prominent among the VTE cases than among the controls corresponding to the data of Kamphuisen et al (33). As stated in the present study, inflammation may affect VTE risk as a procoagulant state may be affected by pro-inflammatory cytokines and chemokines, stimulating monocytes to produce tissue factor (31). Therefore, the present findings indicate that the levels of CRP and IL-6 may be valuable in mediating activation of the coagulation and fibrinolytic process in thrombosis.

Factors, including obesity, hypertension, diabetes, smoking, hypercholesterolemia, cancer, surgery, immobilization, pregnancy and the use of estrogens have been reported to affect the pathogenesis of VTE $(9-11,13,28,31)$. In the present study, it was found that, following adjustment for other risk factors, the CC genotype remained significant between VTE patients and control subjects of the Han and Uyghur populations with an OR of $1.762(95 \% \mathrm{CI}=1.376-5.312)$ for the Han population and an OR of 2.853 (95\% CI=1.248-6.241) for the Uyghur population, respectively. In the significant but rather low OR in the Han population in comparison with that of the Uyghur population, an association was identified between IL-6 levels and VTE, which may represent the residual part, independent of other confounding risk factors. Gene polymorphisms in the IL-6 gene are known to affect IL- 6 production. Whether the existence of a $\mathrm{G}$ allele or the $\mathrm{C}$ allele leads to enhanced IL-6 production remains to be elucidated. A number of studies have identified that increased IL-6 production is associated with the $\mathrm{G}$ allele, while others observed an association with the $\mathrm{C}$ allele $(10,34)$. A further study demonstrated that the high concentration of IL-6 in VTE patients was likely to be due to the presence of VTE rather than a cause of VTE (12). The results of the current study were in accordance with those published by Mahemuti et al (13), which demonstrated an association between IL-6 and CRP levels, as well as VTE and the CC homozygote of the IL-6 $-572 \mathrm{C} / \mathrm{G}$ gene, which was an independent risk factor for VTE. Only a weak statistical significance was identified, which may be due to the small sample size of the Han population. The present study reported for the first time, to the best of our knowledge, an association between the IL- 6 gene and VTE in the Uyghur population in Xinjiang.

Leptin has also been demonstrated in vitro to trigger coagulation by the upregulation of tissue factor (38). Obesity is also linked with higher levels of leptin, an adipokine independently associated with a raised risk for cardiovascular disease (38). Various causative factors and pathological mechanisms have been suggested for the high occurrence of thromboembolism in obesity. Obesity is known as a chronic, low-grade inflammatory state, as evidenced by increased levels of the pro-inflammatory cytokines IL- 6 and TNF- $\alpha$ and acute phase proteins, including CRP. This pro-inflammatory condition is attenuated by weight loss. Besides its direct effects, inflammation can indirectly lead to thrombosis by causing oxidative stress and endothelial dysfunction. In a previous study, it was established that leptin had effects on platelets and endothelial cells through its functional receptor (38). These effects were associated with a prothrombotic tendency. Leptin concentrations used in the present experiments corresponded to that of leptin in the circulation of obese individuals. Thus, it is hypothesized that increased leptin may be a risk factor for thrombosis in obese individuals (39) in accordance with the present study.

In conclusion, the current study presented evidence to suggest that the $-572 \mathrm{G} / \mathrm{C}$ SNP in the promoter region of IL-6 may predict the risk of VTE in the Uyghur and Han populations in Xinjiang. In the present sample of patients from Northern China, VTE was associated with the GC genotype of the $-572 \mathrm{G} / \mathrm{C}$ SNP in the IL- 6 gene. The present study may have clarified the mechanism of VTE and improved understanding of genetic variants and disease-association studies. Undertaking genome wide association studies in different populations certainly merits investigation. The early identification, treatment and prevention of VTE, including lifestyle changes and management for controlling VTE, are major challenges.

\section{Acknowledgements}

This study was supported by the State Key Laboratory Incubation Base of Xinjiang Major Diseases Research Fund (grant no. SKLIB-XJMDR-2012-7).

\section{References}

1. Margaglione $\mathrm{M}$ and Grandone E: Population genetics of venous thromboembolism, A narrative review. J Thromb Haemost 105: 221-231, 2011.

2. Raskob GE, Silverstein R, Bratzler DW, Heit JA, Heit JA and White RH: Surveillance for deep vein thrombosis and pulmonary embolism: recommendations from a national workshop. Am J Prev Med 38: S502-S509, 2010.

3. White RH, Zhou H and Romano PS: Incidence of idiopathic deep venous thrombosis and secondary thromboembolism among ethnic groups in California. Ann Intern Med 128: 737-740, 1998. 
4. Prandoni P and ten Cate JW: Epidemiology, risk factors, and natural history of venous thromboembolism. In: Pulmonary Embolism. Oudkerk M, van Beek EJR, ten Cate JW (eds). Blackwell Science, Berlin, Germany, pp2-32, 1999.

5. Kearon C, Salzman EW and Hirsh J: Epidemiology, pathogenesis, and natural history of venous thrombosis. In: Hemostasis and Thrombosis: Basic Principles \& Clinical Practice. Colman RW, Hirsh J, Marder VJ, Clowes AW and George JN (eds). 4th edition. Lippincott Williams \& Wilkins, Philidelphia, PA, pp 1153-78, 2000.

6. Heit J: Venous thromboembolism epidemiology: implications for prevention and management. Semin Thromb Hemost 28 (Supp 2): 3-13, 2002.

7. Bauer KA: The thrombophilias: well defined risk factors with uncertain therapeutic implications. Ann Intern Med 135: 367-73, 2001.

8. Lensing AWA, Prandoni P, Prins MH and Büller HR: Deep-vein thrombosis. Lancet 353: 479-85, 1999.

9. Jia XW, Tian YP, Wang Y, Den XX and Dong ZN: Correlation of polymorphism in IL-6 gene promoter with BMI, inflammatory factors and pathogenesis and progression of CHD. Zhongguo Shi Yan Xue Ye Xue Za Zhi 15: 1270-1275, 2007 (In Chinese).

10. Fox EA and Kahn SR: The relationship between inflammation and venous thrombosis. A systematic review of clinical studies. Thromb Haemost 94: 362-365, 2005.

11. Vickers MA, Green FR and Terry C: Genotype at a promoter polymorphism of the interleukin- 6 gene is associated with baseline levels of plasma C-reactive protein. Cardiovasc Res 53: 1029-1034, 2002.

12. Christiansen SC, Naess IA, Cannegieter SC, Hammerstrøm J, Rosendaal FR and Reitsma PH: Inflammatory cytokines as risk factors for a first venous thrombosis: a prospective population-based study. PLoS Med 3: e334, 2006.

13. Mahemuti A, Abudureheman K, Aihemaiti X, Hu XM, Xia YN, Tang BP and Upur H: Association of interleukin-6 and C-reactive protein genetic polymorphisms levels with venous thromboembolism. Chin Med J (Engl) 125: 3997-4002, 2012.

14. Mälarstig A, Wallentin L and Siegbahn A: Genetic variation in the interleukin- 6 gene in relation to risk and outcomes in acute coronary syndrome. Thromb Res 119: 467-473, 2007.

15. Reitsma PH and Rosendaal FR: Activation of innate immunity in patients with venous thrombosis: the Leiden Thrombophilia Study. J Thromb Haemost 2: 619-622, 2004.

16. Fan WH, Liu DL, Xiao LM, Xie CJ, Sun SY and Zhang JC: Coronary heart disease and chronic periodontitis: Is polymorphism of interleukin- 6 gene the common risk factor in a Chinese population? Oral Dis 17: 270-276, 2011

17. Basso F, Lowe GD, Rumley A, McMahon AD and Humphries SE: Interleukin-6 $-174 \mathrm{G}>\mathrm{C}$ polymorphism and risk of coronary heart disease in West of Scotland coronary prevention study (WOSCOPS). Arterioscler Thromb Vasc Biol 22: 599-604, 2002.

18. Maitra A, Shanker J, Dash D, John S, Sannappa PR, Rao VS Ramanna JK and Kakkar VV: Polymorphisms in the IL6 gene in Asian Indian families with premature coronary artery disease - the Indian Atherosclerosis Research Study. Thromb Haemost 99: 944-950, 2008.

19. Zheng GH, Chen HY and Xiong SQ: Polymorphisms of $-174 \mathrm{G}>\mathrm{C}$ and $-572 \mathrm{G}>\mathrm{C}$ in the interleukin 6 (IL-6) gene and coronary heart disease risk: a meta-analysis of 27 research studies. PLoS One 7: e34839, 2012.

20. Pan S, Yu ZX, Ma YT, et al: Appropriate body mass index and waist circumference cutoffs for categorization of overweight and centraladiposity among Uighur adults in Xinjiang. PLoS One 8 : e80185, 2013

21. Li SS, Pan S, Ma YT, et al: Optimal cutoff of the waist-to- hip ratio for detecting cardiovascular risk factors among Han adults in Xinjiang. BMC Cardiovasc Disord 14: 93, 2014.
22. Mayinu and Chen X: Evaluation of LOXL1 polymorphisms in exfoliation syndrome in the Uygur population. Mol Vis 17: 1734-1744, 2011.

23. Xu S, Huang W, Qian J and Jin L: Analysis of genomic admixture in uyghur and its implication in mapping strategy. Am J Hum Genet 82: 883-894, 2008.

24. Zhou R, An L, Wang X, et al: Testing the hypothesis of an ancient Roman soldier origin of the Liqian people in northwest China: a Y-chromosome perspective. J Hum Genet 52: 584-91, 2007.

25. Zhou R, Yang D, Zhang H, et al: Origin and evolution of two Yugur sub-clans in Northwest China: a case study in paternal genetic landscape. Ann Hum Biol 35: 198-211, 2008.

26. Xiao FX, Yang JF, Cassiman JJ and Decorte R: Diversity at eight polymorphic Alu insertion loci in Chinese populations shows evidence for European admixture in an ethnic minority population from northwest China. Hum Biol 74: 555-568, 2002.

27. Yang SL, He BX, Liu HL, He ZY, Zhang H, Luo JP, Hong XF and Zou YC: Apolipoprotein E gene polymorphisms and risk for coronary artery disease in Chinese Xinjiang Uygur and Han population. Chin Med Sci J 19: 150-154, 2004.

28. Wang K, Ao Y, Zhao L, et al: Analysis on obesity and its risk factors among inhabitants of Bortala prefecture of Xinjiang autonomous region. Chinese Journal of Public Health 22: 1128-1130, 2006 (In Chinese).

29. Yao J, Ma YT, Xie X, Liu F, Chen BD and An Y: Association of rs1805127 polymorphism of KCNE1 gene with atrial fibrillation in Uigur population of Xinjiang. Zhonghua Yi Xue Yi Chuan Xue Za Zhi 28: 436-440, 2011 (In Chinese).

30. Terry CF, Loukaci V and Green FR: Cooperative influence of genetic polymorphisms on interleukin 6 transcriptional regulation. J Biol Chem 24: 18138-18144, 2000.

31. Malaponte G, Polesel J, Candido S, Sambataro D, Bevelacqua V, Anzaldi M, Vella N, Fiore V, Militello L, Mazzarino MC, Libra M and Signorelli SS: IL-6-174 G > C and MMP-9 1562 $\mathrm{C}>\mathrm{T}$ polymorphisms are associated with increased risk of deep vein thrombosis in cancer patients. Cytokine 62: 64-69, 2013

32. Jordanides N, Eskdale J, Stuart R and Gallagher G: Allele associations reveal four prominent haplotypes at the human interleukin- 6 (IL-6) locus. Genes Immun 1: 451-455, 2000.

33. Kamphuisen PW, Eikenboom JC, Vos HL, Pablo R, Sturk A, Bertina RM and Rosendaal FR: Increased levels of factor VIII and fibrinogen in patients with venous thrombosis are not caused by acute phase reactions. Thromb Haemost 81: 680-683 1999.

34. Vormittag R, Hsieh K, Kaider A, Minar E, Bialonczyk C, Hirschl M, Mannhalter $C$ and Pabinger I: Interleukin- 6 and interleukin-6 promoter polymorphism (-174) $\mathrm{G}>\mathrm{C}$ in patients with spontaneous venous thromboembolism. Thromb Haemost 95: 802-806, 2006.

35. Levi M, van der Poll T and Büller HR: Bidirectional relation between inflammation and coagulation. Circulation 109: 2698-2704, 2004.

36. Morange PE, Bezemer I, Saut N, et al: A follow-up study of a genome-wide association scan identifies a susceptibility locus for venous thrombosis on chromosome 6p24.1. Am J Hum Genet 86: 592-595, 2010.

37. Smeeth L, Cook C, Thomas S, Hall AJ, Hubbard R and Vallance P: Risk of deep vein thrombosis and pulmonary embolism after acute infection in a community setting. Lancet 367: 1075-1079, 2006.

38. Singh P, Peterson TE, Barber KR, Kuniyoshi FS, Jensen A, Hoffmann M, Shamsuzzaman AS and Somers VK: Leptin upregulates the expression of plasminogen activator inhibitor-1 in human vascular endothelial cells. Biochem Biophys Res Commun 392: 47-52, 2010.

39. Maruyama I, Nakata M and Yamaji K: Effect of leptin in platelet and endothelial cells. Obesity and arterial thrombosis. Ann NY Acad Sci 902: 315-319, 2000 